\title{
Improving Young Entrepreneurship Education and Knowledge Management in SMEs by Mentors
}

\author{
Ileana Hamburg, ${ }^{1, *}$ \\ ${ }^{1}$ Institut Arbeit und Technik (IAT) - WH Gelsenkirchen, Germany \\ *Correspondence: Institut Arbeit und Technik (IAT) - WH Gelsenkirchen, Germany. E-mail: hamburg@iat.eu
}

Received: June 30, 2014

Accepted: August 29, $2014 \quad$ Online Published: Ocotber 11, 2014

doi:10.5430/wje.v4n5p51

URL: http://dx.doi.org/10.5430/wje.v4n5p51

\begin{abstract}
Small and medium sized enterprises (SMEs) have a great importance in Europe, but the dynamic nature of market has created a competitive incentive among companies requiring them to improve their critical area of knowledge management (KM) and corresponding skills to create new business. More entrepreneurs, more innovation and growth are necessary and this could be realized particularly by supporting young people who would like to be entrepreneurs but the existing education and training programmes are insufficient.

Mentoring is in comparison with coaching/counselling a special form of active supporting of entrepreneurship competence, a "natural support" helping also young people with special needs to believe in themselves and boost her confidence. The mentoring approach helps young people giving them practical entrepreneurial support and SMEs to improve the transfer and use of strategic knowledge. Knowledge is the key for all organizations and the success of many of them depends on the effective deployment and continual enhancement of their knowledge base so as to be innovative and to remain/become competitive. The paper first describes the areas of research, mentoring, entrepreneurship education and $\mathrm{KM}$ and then used methods and results. Examples for projects supporting the improvement of young entrepreneurship education and KM also by using mentoring are given.
\end{abstract}

Keywords: SME; mentoring; knowledge management; entrepreneurship

\section{Introduction}

Small and medium sized enterprises (SMEs) support local economies accounting about $99 \%$ of all private sector business in Europe (ECORYS, 2012). They are reliable suppliers and partners and work across supply chains of large business facilitating business forward. But European SMEs faced a big number of pressures. More entrepreneurs, more innovation and growth are necessary and this could be realized particularly by supporting young people. Results of interviews done within some European projects show that an increased number of young people would set up own business (i.e. a SME) rather than be employed in another company. The education has an important role in promoting complex entrepreneurial attitudes and behaviours, in supporting ability to turn ideas into action which is i.e. entrepreneurship competence.

Many European countries have on their agenda the improvement of education for entrepreneurship but there exist only isolated initiatives. The vocational and/or high education in almost European countries do not offer realistic understanding of the world of work and SMEs do not support schools and higher institutions in this context also due to lack of resources.

Besides other approaches, the mentoring one explained in chapter 2, which is a powerful personal development tool, helps young people giving them practical entrepreneurial support. Mentoring helps young people to progress in their careers. Mostly it is a partnership between mentor and mentee based on mutual trust and respect.

Mentoring is in comparison with coaching/counselling a special form of active supporting of entrepreneurship competence, a "natural support" helping also young people with special needs to believe in themselves and boost her confidence. Mentoring helps the mentees to explore new ideas in a confidential ambiance, to look more closely at themselves, to reflect on opportunities and wishes.

In part 3 of this paper some requirements for entrepreneurs are given and how could mentors help them (Cull, 2006). 
Another situation within SMEs that can be improved is the lack in implementation of knowledge management (KM). In order to be innovative the use of new knowledge (internally developed or externally acquired) is necessary in order to improve the performance of products, services, processes, work tasks and to grow. But in many European SMEs the used approaches for KM do not support achieving of these objectives. Reasons for this are listed in this paper (Rehman, Mahmood, Sugathan \& Amin, 2010). Mentoring could be organized as a key knowledge management initiative in SMEs particularly for transfer and use of strategic knowledge (Hamburg, 2013a). Examples for projects where mentoring is used for improving young entrepreneurship education and KM in SMEs are given (Hamburg \& O'Brien, 2014).

The paper first describes the areas of research in connection with the problems listed below, the used methods, results and examples.

\section{Description}

The following approaches have been researched and applied in projects coordinated/worked by the author: mentoring, connection with entrepreneurship education and with KM in SMEs.

\subsection{Mentoring}

Mentoring is a human resource development approach and a vital aspect of knowledge management which needs to be looked by all organizations and education institutions wishing to improve their efficiency. A mentoring relationship means usually that one experienced person assists another (or many) to learn, to integrate into an enterprise community, etc. (Bozeman \& Feeney, 2007).

Mentoring has been used in Europe for a long time; it involves guidance and suggestion, as well as the development of autonomous skills, judgments, personal and professional master ship, expertise, trust and the development of self-confidence over the time (O’Brien \& Hamburg, 2014).

Mentoring on the job, where the mentors are companies' employees have advantages because the companies' employees know the work processes, what knowledge is needed for their efficiency and which the companies' knowledge resources are (Kram, 1985). A company that use mentors for newcomers or staff with special needs can have benefits from mentoring by a quick introduction of the mentee into formal and informal company structures and demands, facilitating a deliberate, systematic and smooth transfer of technical or internal knowledge, opportunities to shape the workforce of the future in an international, deliberate way to meet company strategic goals and objectives, training of social competence of the mentee and the mentor.

Mentees meet with a trusted person to achieve i.e. entrepreneurial skills and/or enter into a work place quickly and to cope with initial problems, to discuss and resolve emerging job problems of genuine nature and in relation to the individual needs, learn setting realistic goals and achieving them to acquire new skills and enhance their skills and thus their future career opportunities and prospects in the future through the KT from the mentor, build relationships or interactions allowing them to secure, maintain and advance in the job choosing a way that corresponds to the work routines and social actions of other employees. Mentors improve their personal fulfilment from investing in others, feel valued as a role model, gain a new appreciation, etc.

Different forms of mentors are known. Peer mentoring usually takes place between an experienced person in a domain (mentor) and a person who is new in this context. Peer mentoring differs from classical mentoring first in fact that mentors and mentees are close in age, education level, etc. and that there are semi structured planned programs with specific guidelines and often with a number of activities and meetings in a determined time. In a formal mentoring approach a mentee is paired with a mentor to help him or her to learn the ways of the business world. Most companies either have or are considering implementing a formal mentoring program in the near future. Often formal mentoring programs have specific goals, i.e. to transfer knowledge, advancing career goals, learning business management, or addressing performance deficiencies. But there are cases when the objectives are less structured and are determined by the mentor and mentee as the mentoring unfolds.

In informal mentoring, two people, whose chemistry is compatible, come together to share ideas and learn. One takes the role of the teacher or mentor, the other acts as student or mentee.

\subsection{Mentoring and Entrepreneurship Education}

Many observers from the research community, business and government organizations have stressed the importance of employee education and training in improved productivity and thus to achieve competitive advantage to sustainability. Education and training can assist organizations to establish and sustain a competitive advantage by 
increasing productivity, quality and financial results.

But in many cases SMEs are slow to undertake new forms of training corresponding with market requirements despite the fact that some of them been proven to maintain employee (Ashton \& Felstead, 1995). Stone (2010) reported i.e. that on average $36 \%$ of SMEs do not have any formal training activities and nothing special for young entrepreneurs. Amongst the main reasons for this are (European Commission, 2013; Hankinson, 1994):

- Lack of Time.

- Lack of Funding (Costs).

- Lack of Planning

- Lack of Relevant Courses

- Lack of manager interests for changes.

In this context it is important that education institutions offer a corresponding education for entrepreneurs. One problem is that many education institutions have reduced budget, would like to have a minimum number of students passing tests and no time and resources to cultivate entrepreneurs.

Education for entrepreneurship is already high on the agenda in most EU member states and a variety of programs and activities exist in Europe. But there is a need of promoting these initiatives more systematically. In higher education peer mentoring is used frequently to outreach, retain students being also one cheap alternative to support students where they feel lost. It is intended to expand it also in vocational education. But in both, higher education as well as in VET, special education modules oriented to entrepreneurial competences including transversal skills and attitudes as well as more specialized knowledge and business skills are necessary.

People should be willing to spend time to guide as mentors 19-25 year old youth wishing to become entrepreneurs to develop life plans and put their passions for building a career. Mentors for young entrepreneurs should be from the beginning supporting, tenacious and help young mentees to keep their vision in sight and to reflect what is happening (Cull, 2006). Softer skills such as listening, communicating as well as harder ones to review business plans and stay objectives are necessary. Mentors should maintain mentees motivated encouraging them to persist and at the end to lift off.

Sometimes the mentoring relationship did not work due to lack of communication, commitment, respect or lack of trust in the advice being offered.

Supporting students/starters in small and new business creates a more dynamic area in a local community, more jobs and a more attractive place to do business. Mentors will gain a better understanding of challenges facing small business which could enhance their working life or their retirement period.

\subsection{Knowledge Management in SMEs}

Knowledge management (KM) involves the creation, sharing/dissemination and use/transfer of knowledge. Knowledge management research is widely dispersed and multidisciplinary, it has roots in management, building strategy, technology, innovation and psychology. There have been many approaches to knowledge management but little formal theories developed. Krogh, Jehijo and Nonaka (2000) are the few people who developed a theory for the creation aspect of knowledge management that seems to have stood the test of time.

McElroy (1999) discussed the concept of a knowledge lifecycle with an emphasis towards knowledge processes consisting of individual and group learning, knowledge claim formulation, information acquisition, knowledge validation and knowledge integration. Birkenshaw and Sheehan (2002) developed the concept of a knowledge lifecycle in a different context highlighting that knowledge progresses through five stages, creation, mobilization, diffusion and commoditization. However, with all of these theories there is a presumption that there is willingness on the behalf of the individual and the organization to create, share and use knowledge.

It is known that KM is significant for SMEs and an efficient implementation of KM has positive consequences for SMEs grow and innovation (Salojarvi, Furu \& Sveiby, 2005). Suitable organizational and technological infrastructures of SMEs are enabler for efficient KM. Some organizations have KM infrastructures i.e. in form of KM departments but this is often not possible within SMEs. There is a lack of explicit knowledge repositories in SMEs. One important aspect should be that work is KM organizational oriented and the roles and responsibilities for KM are well defined.

In connection with used technologies, results of projects show that SMEs have significant KM needs but they adopt internal KM procedures based on simple ICT tools and approaches. KM using tacit knowledge based on personal 
relationships and interactions (i.e. in mentoring processes or in work teams) are missing. In small companies KM is limited at data bases with explicit staff contact information (Boudreau, 2003; Bou-Llusar, 2006).

Referring the contribution of mentors to an efficient KM, this is particularly important for strategic knowledge which helps in making decisions and leads to expansion/creation of market and improves the sales in long term. A right decision is often an outcome of experience and this can go out when an employee's retires or leaves. Sometimes the KM approaches in SMEs ignore the importance of strategic knowledge and/or they start with operational and tactical knowledge and do not consider from the beginning the implicit knowledge hidden in minds of experts. The impact of mentors or coaching in this context is essential.

\section{Methods and Results}

The following are particularly results of European projects SIMPEL (www.iat.eu), ReadiSME (www.adam-europe.eu/prj/7498/project_7498_de.pdf) and NetKnowing 2.0 (www.netknowing.com) coordinated or worked by the authors in whom several surveys were conducted with SMEs regarding their barriers to training and $\mathrm{KM}$. To date many efforts to encourage SMEs to adopt training have failed miserably. E-learning has tried to address issues of time and cost, by allowing employees to access learning resources remotely (Hamburg, 2013b). However, technology has significantly changed the way people access information. The most up to date information is dispersed and embedded in networks, websites and social media sites. In addition many SMEs do not have a dedicated human resources person or even an employee that can be charged with the responsibility of searching for relevant learning resources.

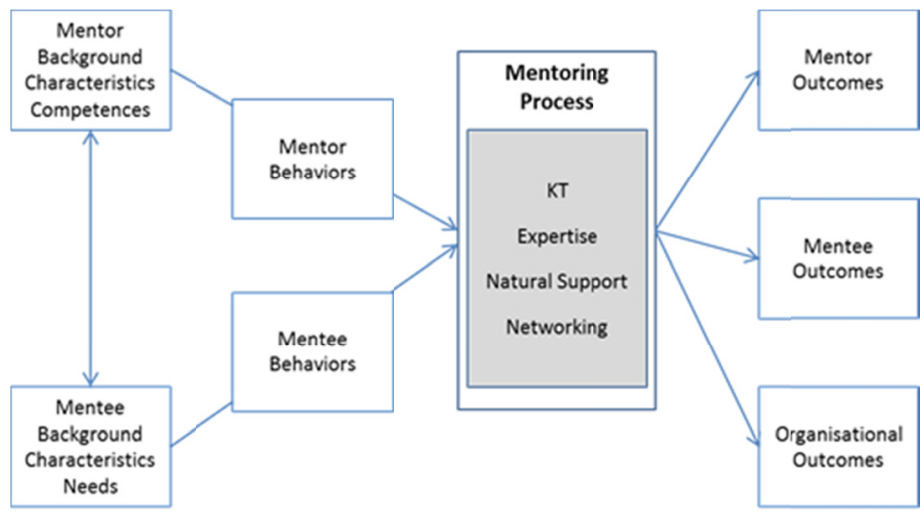

Figure 1. An Efficient Mentoring Process

Source: http://www.naed.org/Presentation.pdf, IAT.

In the following, we present some important aspects we consider in informal and formal approaches which we used in our projects. Informal mentoring has been particularly used for staff with special needs i.e. with disabilities, migration background or seniors who would like to integrate.

Informal mentoring aspects:

- Goals of the relationship are not completely specified

- Outcomes cannot be measured in total

- The process of KT cannot be explicitly described and it is based on the ability and willing for this process

- Access is limited and can be exclusive

- Mentors and mentees are often selected on the basis of personal chemistry, which means an initial connection or attraction between them

- Mentoring lasts a long time

- The organisation benefits indirectly, as the focus is exclusively on the mentee.

These aspects have been considered in the approach of mentoring developed within the project DIMENSAAI (Diversity and Mentoring Approaches supporting Active Ageing and Integration - www.dimensaai.eu) for preparing 
entrepreneurs with special needs in a mentoring process they being mentees in healthcare SMEs.

In the project focus discussion groups have been organised in order to establish the requirements for entrepreneurs and staff in this sector and aspects of mentoring in this context. The consortium intends to improve participation of volunteers in mentor training to improve employment, particularly for disadvantaged young people and to equip such people with the knowledge and skills needed to become entrepreneurs by integrating traditional school subjects with practical entrepreneurship training.

Mentor training has been organised in all project partner countries and informal approaches have been tested.

In Netknowing 2.0 we developed and used an informal mentoring approach taking into consideration aspects like:

- Goals are established from the beginning by the organisation, mentors and mentees

- Outcomes are measured

- Knowledge which has to be transferred is known at the beginning

- Access is open to all who meet the criteria established by the organisation for the corresponding mentoring program

- Mentors and mentees are paired based on compatibility

- Organisation and employees can benefit directly.

One of the conclusions was that in a mentoring relationship experience, skills and desire to help are very important. In order to have a bilateral benefit, open and assertive communication and particularly trust of mentors and mentees are essential.

Referring education of young entrepreneur surveys conducted also by authors with students show that more than $60 \%$ of them would like to become an entrepreneurs. Entrepreneurship refers to individual ability to turn ideas into action. Being an entrepreneur requires (http://under30ceo.com/10-qualities-of-a-successful-entrepreneur/):

- Discipline to follow the business steps of the established strategy every day to achieve the proposed objectives and eliminate the obstacles

- Confidence with own ability and knowledge necessary for established business goals

- Open Minded for new ideas, staff skills, new business

- Self-Starter being proactive and not waiting for someone to give permission

- Competitive, being convince that she/he can do a job better than another

- Creative and problem solving coming with solutions which are synthesis of other items or new ones

- Determination, not believing that something cannot be done

- Communication skills to motivate people to work and to sell products,

- Passion, loving work to be done.

Within the project Net Knowing 2.0 discussions have been organised in VET institutions and SMEs to improve the education of young entrepreneurs by introducing special modules in the curriculum and to introduce business mentoring to help young entrepreneurs. In Germany it has been discussed that potential learning consultants can be trained to act as mentors. Other companies involved decided to use a mentor from the company for a new staff acting as mentee.

The main objective of the on-going European projects ENTER (to) entrepreneurship and Archimede is to support the achieving of entrepreneurial competences and opening minds of young people for innovation and learning by showing them advantages in both professional and everyday life and helping them by mentoring and new technologies.

Referring KM the main methods we used were a literature research and to interview managers and staff responsible with KM in companies. Some results are summarized. In many SMEs, KM seems not to be fully exploited and this is reflected also in little research in this context. One reason of this situation is the lack of support of the management in developing and using KM approaches.

Sometimes owners do not want to share knowledge with employees being afraid of knowledge sharing or lost when the employer leaves. It is also necessary that all levels of management communicate i.e. through corresponding seminars or informal talks about implementation of KM. Then lack of financial resources which has consequences 
for other resources is another problem. Some authors analyse financial resources separately i.e. human ones. Human resource development involving proper training and education for employees and when necessary also mentoring is an important factor in KM.

The culture of the organisation has also a role in the $\mathrm{KM}$ - an organisation where staff is afraid of sharing knowledge with others cannot build efficient KM approaches.

Another problem discussed within the SMEs was to improve KM through the building of local knowledge repositories and using mentors (as facilitators in formal relationships). Mentor training has been planned.

\section{Discussion and Conclusions}

Small and medium sized companies contribute to more than half of European value-added by business and assure economic growth. Many of these companies are small ones, have few resources and difficulties in assuring sustainable KM procedures and adequate training for technological, economic and financial changes. It is known that an increasing number of young people have entrepreneurial ambition, but there is a gap between young people's future aspirations and the reality of their education and training.

The hypothesis that many young people who would like to be entrepreneurs need more entrepreneurial ship experience has been supported by discussions within SMEs, with students in VET and higher institutions and promises made by decision makers to improve the education in this context. It is not sure that enough financial support will be found in all European countries to achieve such objectives.

Results of focus discussion groups with SME staff and education experts organised in the projects shortly presented in this paper, workshops and work sessions organised at different conferences sustain our hypothesis that besides adequate education and training by using formal, informal methods, mentors which are experienced people in this context with skills and qualification in a wide range of industries and discipline can help the staff to refine the business strategy, map out the direction the new/refined business and assist in setting goals improving the situation of SMEs. Our projects partners received many requirements to send information about these approaches and about best practice from projects partner countries in this context as well as invitation to moderate events with the topics of $\mathrm{KM}$ and/or mentoring. Particularly receptive were the former socialist countries from Europe.

The hypothesis that mentoring is a means of facilitating transfer and application of strategic knowledge in SMEs needs more support and we try to give it in our on-going and future projects.

\section{Acknowledgement}

This paper described work within the projects SIMPEL, ReadiSME, NetKnowing 2.0 and DIMENSAAI, sponsored by the Lifelong Learning Program and on-going work in the projects ENTER (to) entrepreneurship and Archimede financed by the European program Erasmus+.

\section{References}

Ashton, D., \& Felstead, A. (1995). Training and Development. Human Resource Management: A Critical Text. S. J. London, Routledge.

Birkinshaw, J., \& Sheehan, T. (2002). Managing the Knowledge Life Cycle. MIT Sloan Management Review, 44(1), 75-83.

Boudreau, J. (2003). Strategic Knowledge Measurement and Management. CAHRS Working Paper Series, Cornell University.

Bou-Llusar, J. (2006). Strategic knowledge transfer and its implications for competitive advantage: an integrative conceptual framework. Journal of Knowledge Management, 10(4), 100-112. http://dx.doi.org/10.1108/13673270610679390

Bozeman, B., \& Feeney, MK. (2007). Toward a useful theory of mentoring: A conceptual analysis and critique. Administration \& Society, 39(6), 719-739. http://dx.doi.org/10.1177/0095399707304119.

Cull, J. (2006). Mentoring Young Entrepreneurs: What Leads to Success? International Journal of Evidence Based Coaching and Mentoring, 4(2), 8-18. 
ECORYS (2012). EU SMEs in 2012 - at the crossroads. Annual report on small and medium-sized enterprises in the EU. Retrieved

from http://ec.europa.eu/enterprise/policies/sme/facts-figures-analysis/performance-review/files/supporting-docum ents/2012/annual-report_en.pdf

European Commission (2013). Competence Development in SMEs. European Observatory for SMEs.

Hamburg, I. (2013a). Facilitating learning and knowledge transfer through mentoring. CSDU 2013: 5th International Conference on Computer Supported Education. Aachen, Germany, 6-8 May. Lissabon, Science and Technology Publications: 4.

Hamburg, I. (2013b). Innovative e-learning solutions and environments for small and medium sized companies (SMEs). In Ghislandi, Patrizia (ed.), Elearning: theories, design, software and applications. Chapter 4. Rijeka: InTech, 53-72.

Hamburg, I., \& O'Brien, E. (2014). Using strategic learning for achieving growth in SMEs. Journal of information technology and application in education, 3(2), 77-83. http://dx.doi.org/10.14355/jitae.2014.0302.04

Hankinson, A. (1994). Small Firms Training: The Reluctance Prevails. Industrial and Commercial Training 1994, 26(9), 28-30. http://dx.doi.org/10.1108/00197859410065889

Kram, K. (1985). Mentoring at work. Developmental relationships in organizational life. Scott, Foresman \& Company, Glenview, ISBN 0-673-15617-6.

Krogh, G., Ichijo, K., \& Nonaka, I. (2000). Enabling Knowledge Creation. How to Unlock the Mystery of Tacit Knowledge and Release the Power of Innovation. New York: Oxford University Press. http://dx.doi.org/10.1093/acprof:oso/9780195126167.001.0001

McElroy, M. (1999). The Knowledge Life Cycle: An Executable Model for the Enterprise ICM. Conference on Knowledge Management.

O'Brien, E., \& Hamburg, I. (2014). Supporting sustainable strategies for SMEs through training, cooperation and mentoring. Higher education studies, 4(2), 61-69. http://dx.doi.org/10.5539/hes.v4n2p61

Rehman, M., Mahmood, A., Sugathan, A., \& Amin, A. (2010). Implementation of Knowledge Management in Small and Medium Enterprises. Journal of Knowledge Management Practice, 11(1), 31-40.

Salojarvi, S., Furu, P., \& Sveiby, K. (2005). Knowledge management and growth in Finnish SMEs. Journal of Knowledge Management, 9(2), 103-122. http://dx.doi.org/10.1108/13673270510590254

Wong, K. Y. (2005). Critical success factors for implementing knowledge management in small and medium enterprises. Industrial Management \& Data Systems, 95(3), 261-279. http://dx.doi.org/10.1108/02635570510590101 